\title{
Product standards, trade disputes, and protectionism
}

\author{
Daniel M. Sturm Department of Economics, University of \\ Munich
}

\begin{abstract}
Disputes over national product standards are a major source of tension in international trade negotiations. The usual pattern is that exporters challenge new product standards as a 'disguised barrier to trade.' The paper develops a two-country political agency model of standard setting. It is shown that there exists a political equilibrium in which the importing country on average applies a more stringent standard than the exporting country. This difference can be due either to a too lax standard in the exporting country or a too stringent standard in the importing country. JEL classification: F18, F13, D72
\end{abstract}

Normes pour les produits, désaccords commerciaux entre pays, et protectionnisme. Les désaccords à propos des normes nationales pour les produits sont une source majeure de tension dans les négociations du commerce international. Le pattern usuel des débats est que des exportateurs condamnent les nouvelles normes pour les produits comme des «barrières déguisées au commerce». Le mémoire développe un modèle politique de définition de normes pour deux pays. On montre qu'il existe un équilibre politique pour lequel le pays importateur impose en moyenne des normes plus exigeantes que le pays exportateur. La différence peut être attribuable soit à des normes trop molles dans le pays exportateur soit à des normes trop rigoureuses dans le pays importateur.

This paper builds on chapter two of my PhD thesis at the London School of Economics. I would like to thank Tim Besley, Peter Neary, and Tony Venables for their help throughout the project. I am also indebted to Brian Copeland, Gilles Duranton, Jose Madeira, Niko Matouschek, Stephen Morris, Carol McAusland, Paolo Ramezzana, Steve Redding, Sönje Reiche, Till Requate, Alan Winters, two anonymous referees, and numerous seminar participants for discussions and comments. Financial support from the European Commission through a Marie Curie Fellowship is gratefully acknowledged. The usual disclaimer applies. Email: daniel.sturm@Imu.de 


\section{Introduction}

Attempts to reduce non-tariff barriers to trade are currently at the heart of international trade negotiations. The arguably most difficult issue in this area is trade disputes over national product standards. The usual pattern is that a country introduces a new product standard applying to all sales of particular goods in the domestic market, which is justified as necessary for consumer or environmental protection. Foreign firms exporting to the domestic market, however, challenge the standard as a 'disguised barrier to trade' or simply 'green protectionism,' the exact meaning of these phrases clearly being hotly disputed.

One prominent example is the 'beef hormones' dispute between the European Union and the United States. After allegations that the consumption of beef from cattle that have been treated with growth hormones could pose a risk to human health, the EU banned the sale of all hormone-treated beef in January 1989. In the United States the hormones in question continue to be allowed and are widely used. The United States has repeatedly challenged the ban as not based on the available scientific evidence and therefore constituting a disguised barrier to trade. The EU defends the ban on the grounds that it has the right to implement whatever regulation it considers necessary to protect European consumers. ${ }^{1}$

Many similar cases have kept trade negotiators busy. The United States and Japan, for example, have long argued about appropriate standards for food additives. Similarly, the member countries of the EU have in the past had an intense struggle over emission standards for cars. The continuous introduction of new production technologies, such as genetically modified food, also makes it unlikely that opportunities to disagree about appropriate product standards will decline in the future.

From the anecdotal evidence one can distill three stylized facts. First, there is usually some genuine uncertainty about the environmental or safety benefits of the disputed regulation. Scientific consensus can rarely offer near certainty about the likely damage a product could cause, in particular in the early phase after initial allegations of harm. Second, there tends to be substantial asymmetric information between policy makers and the general public. Given the complexity and number of such disputes, it is unlikely that voters will find it optimal to be as well informed about the scientific evidence as government agencies. Finally, even though the product regulation is usually applied in a non-discriminatory way to both domestic firms and foreign firms exporting to the domestic market, the immediate cost impact of the regulation is usually non-uniform, with higher costs falling on foreign firms exporting to the domestic market. In the beef hormones case U.S. producers would, for

1 For a more detailed summary of this and other trade disputes over product standards see Vogel (1995) and Esty (1994). Engel (2000) contains an extensive case study of the BSE crisis and a dispute between Venezuela and the United States. 
technical reasons, have to bear substantial additional costs if they wanted to supply the European market with hormone-free beef while maintaining the use of these hormones for the U.S. market. In other cases, the new product standard also tends to change the relative cost structures of foreign firms exporting to the domestic market and domestic firms in favour of domestic firms, which is the very basis of the trade barrier argument.

The purpose of this paper is to develop a two-country political economy model that can explain such disputes over product standards and to build on the stylized facts introduced above. The basic mechanism that drives our results is simple. Some politicians would like to subsidize a local industry. However, this is not in the interest of the majority of the population. Politicians can use two different instruments to support the local industry. They can either use an efficient direct transfer or manipulate a product standard. In line with the stylized facts, we assume that the optimal level of this standard is uncertain. Faced with this choice, politicians, who are electorally accountable for their policy choices, will sometimes prefer to use the product standard to protect the local industry. The reason is that the uncertainty about the optimal level of the standard allows the politician to disguise his transfer, which in turn reduces the electoral penalty for his policy choice.

This mechanism has a number of interesting implications. First, we show that politicians' use of the product standard as a disguised transfer can explain the observed pattern of trade disputes. There exists a political equilibrium in which the importing country sets a stricter product standard than the exporting country. Second, such a difference in standards can be due either to an excessively strict standard in the importing country or to a too lax standard in the exporting country. Interestingly, both of these cases are observationally equivalent in the model.

The interaction between environmental policy and international trade has been the subject of a large literature over the last decade. See, for example, Copeland and Taylor (2003), Rauscher (1997), and Sturm (2003) for recent surveys. However, the possibility that product regulations could become disguised barriers to trade, which has been discussed widely among policy makers, has received little attention in this literature. Notable exceptions are Esty (1994), Laplante and Garbutt (1992), Sorsa (1995), and Engel (1999), who informally discuss the problem of product regulations as disguised barriers to trade and possible solutions.

Fischer and Serra (2000) present an international duopoly model with perfect information. The home government is welfare maximizing and unilaterally imposes a product standard. Their main result is that, in the absence of other policy instruments, a product standard can be used as an indirect trade policy to shift rents from the foreign to the domestic firm. Similar models are also analysed in Copeland (2001) and Tian (2003). Copeland (2001) explores to what extent a national treatment rule can prevent the home government from manipulating the product standard in favour of the home firm. Tian (2003) 
shows that imposing a more stringent product standard on imports may not increase the profits of the home firm. She then introduces a political support function for the home government and characterizes under what circumstances a tighter product standard for imports increases political support in the home country. Our paper, in contrast, presents a political agency model that stresses the importance of imperfect information in disputes over product standards and explicitly models the interaction between the home and foreign government.

There is also a small literature on the political economy of environmental policy in an open economy. Fredriksson (1997) and Aidt (1998) are two examples that analyse the choice of emission taxes in a small open economy within a common agency framework. Hillman and Ursprung (1992, 1994) introduce an environmental lobby into a lobby model of trade policy formation. In their model the environmental lobby tries to influence trade policy to reduce emissions, while more direct environmental policy instruments are assumed to be absent. In contrast, in this paper distortions of environmental policy are at the centre of the analysis.

The idea that politicians may have an incentive to use inefficient instruments to make disguised transfers to particular groups in the population has a long tradition in the 'Virginia School' of political economy. See, for example, the arguments in Tullock $(1983,1989)$. This idea was formalized by Coate and Morris (1995), who assume that voters are rational but imperfectly informed about the consequences of different policies. Our approach to modelling the uncertainty about the optimal product standard is very similar to the set-up in Coate and Morris (1995). In contrast to them, we consider a two-country model with yardstick competition between the politicians. ${ }^{2}$

\section{The model}

\subsection{Economic environment}

The economy is modelled as a specific-factors model. Two large countries, home and foreign, trade a numeraire good $n$ and good $x$. There are two factors of production, labour and a specific capital stock. Each country is populated by a politician, a representative producer, and a representative consumer, who represents the majority of the population. The two countries are symmetric unless otherwise stated and only the home country will be described. All foreign variables carry an asterisk.

The home representative consumer supplies $L$ units of labour and has the quasi-linear utility function

2 Besley and Case (1995a, 1995b, 2003) and List and Sturm (2006) provide empirical evidence from gubernatorial elections in the United States for the explanatory power of political agency models. Alesina, Baqir, and Easterly (2000) and Alesina, Danninger, and Rostagno (2001) present data on public employment that are consistent with the disguised transfer mechanisms modelled by Coate and Morris (1995). 


$$
U=n+u(x),
$$

where $x$ is consumption of good $x$. We assume that $u^{\prime}>0$ and $u^{\prime \prime}<0$. The politician and the representative producer consume only the numeraire good. The consumer price of good $x$ is $p$ and the producer price is $p_{p}$. The numeraire good is produced with a constant returns to scale technology, which uses one unit of labour to produce one unit of output. Good $x$ is produced with the technology

$$
q_{x}=f\left(l_{x}, k\right),
$$

where $q_{x}$ denotes home output of good $x, k$ is the specific capital stock, and $l_{x}$ is the amount of labour that is used in the production of good $x$ in home. The production function is assumed to have constant returns to scale and diminishing returns to each factor. The returns accruing to the two specific capital stocks are earned by the local producer in each country and are denoted $\pi$ and $\pi^{*}$, respectively. We assume that labour supply is sufficiently large to always ensure positive production in the numeraire sector. To generate trade flows, we assume that the two otherwise identical countries differ in their endowment with the specific capital stock, which is assumed to be larger in the foreign country. This implies that the foreign country has a comparative advantage in good $x$ and exports it under free trade.

Consumption of good $x$ causes damage. This damage has a number of important properties. First, it is only caused by the consumption of units of good $x$ that come from foreign production. Consumption of such units in home and foreign is denoted $x_{F}$ and $x_{F}^{*}$, respectively. This assumption is an extreme way of capturing the stylized fact, introduced above, that the impact of the product regulation is generally non-uniform, with higher costs falling on foreign firms exporting to the domestic market. In a more general model the damage would be caused by both domestically and foreign-produced units of good $x$, and the non-uniform impact would be generated by different abatement costs in the domestic and foreign industries.

Second, the damage is uncertain. Damage depends on a state of nature $\theta \in$ $\left\{\theta_{0}, \theta_{1}\right\}$. Expected damage $D$ in the home country is

$$
D\left(\theta, x_{F}\right)=\theta x_{F} .
$$

With probability $\theta$, damage is proportional to consumption of units of $x$ from foreign production, and with probability $(1-\theta)$ there is no damage. Damage is measured in units of the numeraire. We assume that $\theta_{0}<\theta_{1}$ and refer to $\theta_{1}$ as the 'high risk' and $\theta_{0}$ as the 'low risk' state. The uncertainty about the harmfulness of $x_{F}$ captures the idea that the scientific consensus offers only a probability estimate of the likely damage. Note that it is never possible to infer ex post the state of nature $\theta$ from the realized damage.

Third, at least part of the damage is an externality. If damage due to consumption of units of $x_{F}$ were entirely private costs, then there would be 
no obvious reason for government intervention. However, as long as some part of the damage is external, there remains a role for government intervention, which is what we observe in practice. We will make the simplifying assumption that the damage is a pure externality. It would not be difficult to extend the model so that some part of the damage is private costs. ${ }^{3}$ Finally, we also make the simplifying assumption that the damage is borne only by the consumer, not by the producer and politician.

Damage can be avoided with the help of an abatement technology. The expected damage of foreign produced units $x_{F}$ can be reduced to zero at constant marginal costs of $a$ units of labour per unit of $x_{F}$ treated. The abatement activity can be thought of either as a separate sector or as an extra production cost incurred by the foreign $x$ industry for output shipped to a market that requires the application of the abatement technology.

There are two policy instruments. The first policy instrument is the environmental policy $E \in\{N, P\}$. The policy maker can implement a product standard $P$, which requires that all foreign-produced units of good $x$ are treated with the abatement technology before they are sold in the local market. The alternative option $N$ is to do nothing. If the domestic politician, for example, implements the product standard $(E=P)$ while the foreign politician decides to do nothing $\left(E^{*}=N^{*}\right)$, then all foreign produced units of $x$ that are exported to the home country are treated with the abatement technology, while any units sold in the foreign market remain untreated. The second policy instrument is a lump-sum transfer $T$ to the producer. This transfer is financed by a lump-sum tax on the consumer.

\subsection{Optimal policy and profits}

The welfare consequences of implementing the product standard $P$ in the home country can be evaluated with the following welfare function,

$$
W=\mathrm{Cs}+\pi-D\left(\theta, x_{F}\right),
$$

where CS is consumer surplus. The optimal environmental policy clearly depends on the relative magnitude of the damage parameters $\theta_{0}, \theta_{1}$ and the abatement costs $a$. If $a$ is, for example, sufficiently large relative to $\theta_{0}$ and $\theta_{1}$, then it would never be optimal to use the abatement technology. To ensure that there is an interesting policy problem we make the following assumption:

ASSUMPTION 1. $\theta_{1}\left(\theta_{0}\right)$ is sufficiently large (small) relative to the marginal abatement costs a that (not) implementing the product standard is the welfare maximizing policy in both countries if $\theta=\theta_{1}\left(\theta=\theta_{0}\right)$.

This assumption implies that there is a simple optimal policy, which will be the benchmark against which we compare the outcome of the political process.

3 A technical issue is that it may seem odd that there can be an externality even though there is only one representative consumer. However, it would not be difficult to introduce many identical consumers who impose an externality on each other. 
If politicians only maximize social welfare, then there would never be any disagreement about the product standard between the two countries. Both countries would implement the product standard if expected damage is high $\left(\theta=\theta_{1}\right)$ and not do so otherwise. ${ }^{4}$

The product standard also affects the profits of the domestic and foreign industry in a straightforward way. Implementing the product standard in the home country increases the costs of exporting to the home country. As a result, the domestic price of good $x$ will increase, while the (producer) price in the foreign country will decrease until $p=p_{p}=p_{p}^{*}+a$. As profits are an increasing function of the producer price, this implies that the profits of the producer of good $x$ in the home country increase, while those of the producer in the foreign country fall.

Application of the product standard in the foreign country increases the cost of supplying its local market for the foreign industry. As a result, the foreign producer price for good $x$ will decline, while the foreign consumer price will increase until $p^{*}=p_{p}^{*}+a$, which reduces the profits of the foreign industry. ${ }^{5}$ Finally, in response to the increased costs of supplying its local market the foreign $x$ industry will increase its exports, which will reduce the profits of the home $x$ industry. The results of this discussion are summarized in the following lemma.

LEMMA 1. Implementing the product standard in the home country increases the profits of the domestic industry that produces good $x$ and reduces those of the foreign industry. Implementing the regulation in the foreign country reduces the profits of both the domestic and the foreign industry that produces good $x$.

\section{The political system}

The political system is modelled in the spirit of the political agency literature. We consider a two-period model. The structure of the domestic and foreign political system are identical.

4 The preferred policy of the consumer may not coincide with the welfare maximizing policy, since he does not earn the returns to the specific capital stock. If $\theta_{1}$ is sufficiently large and $\theta_{0}$ sufficiently small relative to $a$, then we can abstract from such straightforward complications.

5 Note that in the case where only the foreign country implements the product standard, it is not possible for the foreign $x$ industry to entirely avoid using the abatement technology by selling its entire output in the home country, while the foreign country would be supplied by the home $x$ industry. As we assume that the two countries are symmetric, foreign has a comparative advantage in good $x$ and the abatement castes are sufficiently small to not prohibit trade entirely, the foreign $x$ industry will always sell parts of its output in its local market and arbitrage therefore ensures that $p=p_{p}=p_{p}{ }^{*}=p_{p}{ }^{*}-a$. 


\subsection{Politicians}

Politicians come in two types, 'good' and 'bad.' A good politician is a straightforward person who always implements the welfare-maximizing environmental policy and does not make any direct transfers. ${ }^{6}$

A bad politician's preferences are more interesting. His per period utility function is $v_{b}(W, \pi+T)$; that is, the income of the local producer enters his utility not only as one component of welfare, but also as an additional argument. We assume that $v_{b}$ is smooth, increasing in welfare, and strictly concave in both arguments. Furthermore, we assume that it is increasing in $\pi+T$ at $T=0$ but decreasing above some higher level of income of the local industry; that is, a bad politician would like to transfer some resources to the local producer but not an infinite amount. There are no explicit micro-foundations for these preferences. One possible justification would be that the bad politician is susceptible to bribes from the well-organized producer lobby. We also assume that bad politicians discount second-period utility with the discount factor $\beta$.

Since welfare and profits are a function of the environmental policy choice, we can write a bad politician's per period utility function as $v_{b}\left(W\left(E, E^{*}, \theta\right)\right.$, $\left.\pi\left(E, E^{*}\right)+T\right)$ or simply $v_{b}\left(E, E^{*}, T, \theta\right)$. The key assumption about the preferences of a bad politician is as follows:

ASSUMPTION 2. It is the case that $\psi_{1}>0$ and $\psi_{1}^{*}>0$ with

$$
\begin{aligned}
& \psi_{1}=v_{b}\left(P, N^{*}, 0, \theta_{0}\right)-v_{b}\left(N, N^{*}, 0, \theta_{0}\right) \\
& \psi_{1}^{*}=v_{b}^{*}\left(P, N^{*}, 0^{*}, \theta_{1}\right)-v_{b}^{*}\left(P, P^{*}, 0^{*}, \theta_{1}\right) .
\end{aligned}
$$

This assumption says that, given that no direct transfer has been made, for a bad domestic (foreign) incumbent the increase in income of the local producer more than compensates the loss in welfare caused by the unwarranted (non) implementation of the environmental policy in the 'low risk' state $\theta_{0}$ ('high risk' state $\theta_{1}$ ). The size of $\psi_{1}$ and $\psi_{1}^{*}$ is a measure of the relative weight that a bad politician attaches to welfare and the income of the local producer. Large values of $\psi_{1}$ and $\psi_{1}^{*}$ imply that he attaches a low weight to social welfare. If assumption 2 did not hold, then bad incumbents would not really be harmful, since they would never want to abuse the environmental policy.

Finally, we introduce a measure of the re-election incentives of the incumbents in the first period. Let $\hat{T}$ be the direct transfer that maximizes a bad domestic politician's utility for given environmental policy choices $E$ and $E^{*}$ and state $\theta$. That is:

6 The simple modelling of the good politician could be relaxed at the cost of some more complexity, as is done in Coate and Morris (1995). However, all interesting equilibria of such a more general model involve the good politicians maximizing welfare and not making any cash transfers, which would have to be ensured through restrictions on the preferences of good politicians. 


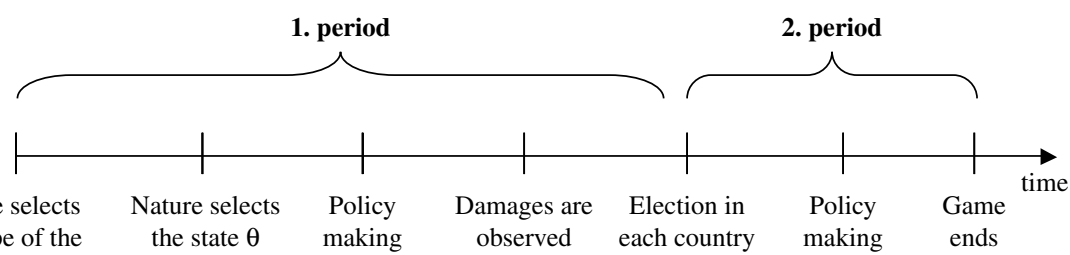

the type of the the state $\theta$ making observed each country making ends incumbent in (private knowledge

each country of the incumbents)

(private knowledge

of each incumbent)

FIGURE 1 Timing and information

$$
\hat{T}\left(E, E^{*}, \theta\right)=\underset{T}{\arg \max } v_{b}\left(E, E^{*}, T, \theta\right) .
$$

The resulting utility level is denoted $\hat{v}_{b}\left(E, E^{*}, \hat{T}, \theta\right)$. Similarly $\hat{T}^{*}$ is the optimal transfer for a foreign bad politician, which results in utility $\hat{v}_{b}^{*}\left(E, E^{*}, \hat{T}^{*}, \theta\right)$. Now define $\psi_{2}$ and $\psi_{2}^{*}$ as

$$
\begin{aligned}
& \psi_{2}=\min _{E, E^{*}, \theta}\left\{\beta \hat{v}_{b}(\hat{T})-\left[\hat{v}_{b}\left(E, E^{*}, \hat{T}, \theta\right)-v_{b}\left(E, E^{*}, 0, \theta\right)\right]\right\} \\
& \psi_{2}^{*}=\min _{E, E^{*}, \theta}\left\{\beta \hat{v}_{b}^{*}\left(\hat{T}^{*}\right)-\left[\hat{v}_{b}^{*}\left(E, E^{*}, \hat{T}^{*}, \theta\right)-v_{b}^{*}\left(E, E^{*}, 0^{*}, \theta\right)\right]\right\} .
\end{aligned}
$$

The term $\hat{v}_{b}\left(E, E^{*}, \hat{T}, \theta\right)-v_{b}\left(E, E^{*}, 0, \theta\right)$ in square brackets in equation (6) is the utility that a bad domestic politician forgoes if he does not implement the direct transfer in the first period as a function of $E, E^{*}$, and $\theta$. This is subtracted from the maximal discounted second-period payoff of the domestic incumbent $\beta \hat{v}_{b}(\hat{T})$, which is a function only of $\hat{T}$, since - as discussed below there is no environmental policy problem in the second period. Hence, $\psi_{2}$ and $\psi_{2}^{*}$ are a lower bound on the re-election incentives of the incumbents. Large values of $\psi_{2}$ and $\psi_{2}^{*}$ correspond to large re-election incentives for the incumbent. In this case, discounted maximal second-period payoff of a bad politician is large relative to the utility that he forgoes by not implementing his preferred transfer in the first period.

\subsection{Timing of events and information structure}

The timing of the game is summarized in figure 1. At the beginning of the first period, nature moves and selects the type of the incumbent in each country. Their own type is private knowledge of each incumbent. Then all agents receive a noisy signal $\lambda_{I}$ and $\lambda_{I}^{*}$ with $0<\lambda_{I}^{*}, \lambda_{I}<1$ of the type of the incumbents. The value of $\lambda_{I}$ and $\lambda_{I}^{*}$ is the probability that the domestic and the foreign incumbent, respectively, is good and will also be referred to as an incumbent's initial reputation. Then nature moves again and selects the state $\theta$. With probability $\phi$, which is also common knowledge, the state is $\theta_{1}$. 
The key informational assumption is that the realization of $\theta$ is observed by only the two incumbents. This captures the idea that the incumbents have an advantage in assessing the scientific evidence on the riskiness of the externality. They can, for example, commission a study which reveals the state $\theta$ but the results of this study cannot be credibly conveyed to the voter. Furthermore, the assumption that both incumbents observe the state $\theta$ ensures that any disagreement between the politicians about the optimal policy is not caused by different information about the state of nature.

After observing the state of nature, the two incumbents simultaneously implement their environmental and transfer policies. At the end of the first period the realized damage is observed by all agents and there is an election in both countries. The voter in this election is the representative consumer, who represents the majority of the population. The election is a contest between the incumbent and a challenger. The domestic and the foreign challenger have initial reputations $\lambda_{C}$ and $\lambda_{C}^{*}$, respectively, which are the voters' beliefs of the probability that the challengers are of the good type. The challengers' reputations are drawn from a common cumulative distribution function $G(\lambda)$, which is smooth and increasing and satisfies $G(0)=0$. The winner of the election is in office in the second period. For simplicity, the only available policy instrument in the second period is the direct transfer. Then the game ends.

\subsection{Equilibrium definition}

A political equilibrium in this model is a perfect Bayesian equilibrium of the game between the politicians and the representative voters. A strategy for each type of politician is a function that specifies the probability with which he implements the two policies as a function of the realization of $\theta$, his own type, the realization of $\lambda_{I}$ and $\lambda_{I}^{*}$ and time. A strategy for the representative voter in each country consists of two parts. The first part is a set of beliefs about the quality of the incumbent, which are generated by Bayes' rule where possible. The second part is a rule that specifies the probability with which the voter re-elects the incumbent as a function of the reputation of the challenger and the updated beliefs about the incumbent.

\section{Political equilibrium}

The game will be solved backwards in the usual way. The political equilibrium in the second period is straightforward. In the second period, bad politicians are no longer constrained in their behaviour by re-election concerns. A bad politician in the home country maximizes his utility by implementing his preferred transfer $\hat{T}$, which results in utility $\hat{v}_{b}(\hat{T})$. Similarly, a bad foreign politician will chose $\hat{T}^{*}$, which results in utility $\hat{v}_{b}^{*}\left(\hat{T}^{*}\right)$.

The political equilibria in the first period are more interesting. In particular, we will show that there is an equilibrium in which the home country, which imports good $x$, implements the product regulation, while the foreign country 
does not do so. The first-period equilibrium strategies in this equilibrium are as follows. Bad domestic politicians always implement the product regulation regardless of the state $\theta$ and do not use the transfer $T$. Bad foreign incumbents, in contrast, never implement the product regulation and also do not use the transfer $T^{*}$.

For these equilibrium strategies, updated beliefs $\alpha$ of the voter in home about his incumbent if the product standard was implemented in home but not in foreign, if no direct transfers have been undertaken, and if damage has occurred, denoted as $\bar{D}$, are

$$
\alpha\left(P, N^{*}, 0,0^{*}, \bar{D}\right)=\frac{\lambda_{I}\left[\left(1-\lambda_{I}^{*}\right) \phi \theta_{1}\right]}{\lambda_{I}\left[\left(1-\lambda_{I}^{*}\right) \phi \theta_{1}\right]+\left(1-\lambda_{I}\right)\left[\begin{array}{c}
\lambda_{I}^{*}(1-\phi) \theta_{0} \\
+\left(1-\lambda_{I}^{*}\right)\left\{\phi \theta_{1}+(1-\phi) \theta_{0}\right\}
\end{array}\right]} .
$$

The numerator of this expression is the probability that a good domestic incumbent would have generated the track record $\left(P, N^{*}, 0,0^{*}, \bar{D}\right)$. The denominator is the probability that this track record is generated at all. Beliefs for the track record $\left(P, N^{*}, 0,0^{*}, 0\right)$ and the beliefs of the foreign voter for these two track records are very similar.

These beliefs have a number of intuitive properties. First, it is not difficult to verify that $\partial \alpha / \partial \lambda_{I}>0$ and $\partial \alpha / \partial \lambda_{I}^{*}<0$; that is, updated beliefs of the domestic voter are increasing in the domestic incumbent's initial reputation and decreasing in the foreign incumbent's initial reputation. Similarly, it is also the case that $\partial \alpha^{*} / \partial \lambda_{I}^{*}>0$ and $\partial \alpha^{*} / \partial \lambda_{I}<0$. That updated beliefs are increasing in the incumbent's initial reputation is intuitive. That the updated beliefs depend negatively on the reputation of the incumbent in the other country is due to yardstick competition between the two incumbents. Voters observe both incumbents' policy choices and know that the same policy is appropriate in both countries. Disagreeing with the other incumbent therefore becomes more costly, in terms of a reduction in the voter's updated beliefs about his incumbent, if the voter's evaluation of the quality of the incumbent in the other country increases.

Second, it is also not difficult to check that for the domestic incumbent $\alpha\left(P, N^{*}\right.$, $\left.0,0^{*}, 0\right)<\alpha\left(P, N^{*}, 0,0^{*}, \bar{D}\right)<\lambda_{I}$; that is, updated beliefs about the incumbent are always worse than the initial reputation if the two incumbents disagree over the product standard. Similarly, $\alpha^{*}\left(P, N^{*}, 0,0^{*}, \bar{D}\right)<\alpha^{*}\left(P, N^{*}, 0,0^{*}, 0\right)<\lambda_{I}^{*}$. The reason is that disagreement can arise only if at least one incumbent is of the bad type. Observing disagreement over the product regulation makes it more probable that one's own incumbent is bad, but not certain, since the disagreement could be due to a bad incumbent in the other country.

As usual, Bayes' rule can pin down only beliefs on the equilibrium path. For the equilibrium strategies of bad incumbents direct transfers are an out of equilibrium event. We make the mild assumption that out of equilibrium 
beliefs are zero in this case. The following proposition characterizes under which conditions the strategies outlined above are an equilibrium:

PROPOSITION 1. For sufficiently high values of $\psi_{1}, \psi_{1}^{*}, \psi_{2}, \psi_{2}^{*}$ there exists a range of initial reputations $\lambda_{I}$ and $\lambda_{I}^{*}$ in which a strategy for a bad domestic (foreign) incumbent always (never) to implement the product standard and for both incumbents not to make any direct transfers is a perfect Bayesian equilibrium.

The appendix contains a formal proof of this claim. To understand the intuition for this result, consider the incentives faced by a bad domestic incumbent in the 'low risk' state $\theta_{0}$. Implementing the product standard and the transfer are two alternative means of increasing the income of the domestic producer for a bad politician. Everything else equal, he would prefer to use the transfer to increase the producer's income, since implementing the product standard is distortionary in the low-risk state and even bad incumbents care about welfare.

However, the re-election incentive can dominate this effect. As implementing the transfer signals to the voter with certainty that the incumbent is of the bad type, it entails certain electoral defeat. The electoral consequences of the product standard are less severe. It also reduces the re-election probability of the incumbent, but not all the way to zero. If bad incumbents in home attach a low weight to social welfare (which corresponds to a high $\psi_{1}$ ) and re-election is sufficiently valuable (which corresponds to a high $\psi_{2}$ ), then bad incumbents prefer to distort the environmental policy to indirectly transfer income to the local producer.

The political equilibrium characterized in proposition 1 differs markedly from the policies that purely welfare-maximizing politicians would implement. In this equilibrium, a bad domestic incumbent, for example, implements the product standard even in state $\theta_{0}$, when doing so is not optimal on welfare grounds. We will refer to such an unwarranted implementation of the product standard as 'green protectionism.' The environmental policy is implemented not because of its environmental benefits, but as an indirect way of transfering resources to the local industry.

Such green protectionism is a political failure in the sense of Besley and Coate (1998), since we are below the constrained second-best utility possibility frontier. Instead of implementing the environmental policy in state $\theta_{0}$, the bad politician could use the available transfer policy to pay the producer of good $x$ the equivalent of the increase in profits that he enjoys under the product standard. This would leave the producer indifferent and make the consumer better off. The politician's first-period utility would also increase as welfare increases, while the producer's income would stay the same. The available policy instruments could therefore achieve a Pareto improvement, but the bad politician does not find it in his best interest to bring it about, owing to the different effects of the two policy instruments on his re-election probability. 
Similarly, in the equilibrium of proposition 1, a bad foreign incumbent does not implement the product standard even in the 'high risk' state $\theta_{1}$. We will refer to this underprovision of environmental policy as 'environmental dumping,' and it also constitutes a political failure in the sense defined above. Rather than exposing the foreign consumer to the 'high risk' externality, the foreign politician could implement the product standard and compensate the foreign producer of good $x$ for the fall in profits. This would increase the foreign consumer's utility and therefore also the foreign politician's first-period utility.

We will refer to a situation in which the domestic politician implements the product standard while the foreign incumbent does not as a 'trade dispute.' Such a difference in the environmental policy choice will result in mutual accusations for two reasons. First, from lemma 1, we know that implementing the product standard in the home country reduces the price of good $x$ in the foreign country, which is a deterioration in the terms of trade of the foreign country. So both good and bad foreign politicians will oppose such a decision, which reduces both the profits of the foreign producer and foreign welfare. Second, there is yardstick competition between the two incumbents. Disagreement over the environmental policy reduces the re-election chances of both incumbents, because voters infer that at least one incumbent is of the bad type. The politician who is distorting the environmental policy therefore imposes a negative reputational externality on the other incumbent.

An interesting implication of the equilibrium characterized in proposition 1 is that green protectionism and environmental dumping are observationally equivalent from the perspective of the voters. If there is disagreement about the appropriate environmental policy, then it is clear that one incumbent is abusing the environmental policy. However, it is impossible for the voters to distinguish between cases in which the domestic environmental policy is too strict and cases in which the foreign environmental policy is too lax.

What is the importance of the yardstick competition between the two incumbents for the results derived so far? The yardstick competition is a constraint on bad incumbents' (mis-)behaviour. Disagreeing with a very reputable incumbent in the other country carries a high re-election penalty in the equilibrium characterized in proposition 1 and therefore becomes progressively less attractive. An alternative assumption would be that voters cannot observe policy choices in the other country. The appendix shows that in this case the equilibrium characterized in proposition 1 becomes an equilibrium in a larger parameter space. This is summarized in the following corollary:

COROLLARY 1. In a world without yardstick competition there exists a larger range of initial reputations $\lambda_{I}$ and $\lambda_{I}^{*}$ in which the strategies of proposition 1 form a perfect Bayesian equilibrium for any given values of $\psi_{1}, \psi_{1}^{*}, \psi_{2}, \psi_{2}^{*}$.

This corollary allows us to compare our results with those of Coate and Morris (1995). The model without yardstick competition, where each country sets its 
policy in isolation, is very close to their set-up. This corollary therefore says that the inefficiencies that Coate and Morris (1995) have identified are an equilibrium in a smaller range of parameters in the presence of yardstick competition between two incumbents, but they continue to exist.

\section{Conclusion}

This paper has addressed the growing number of trade disputes over product standards. We have developed a two-country political agency model that can generate the observed disputes over product standards as a political equilibrium. The mechanism behind this result is that politicians, who are electorally accountable for their policy choices, sometimes prefer to use the product standard as a disguised transfer mechanism to support a local industry. The model shows that trade disputes can be due to either an excessively strict standard in the importing country or a too lax standard in the exporting country, and both cases are observationally equivalent.

\section{Appendix}

\section{Proof of proposition 1}

Updated beliefs of the domestic voter after the first-period track record $\left(P, N^{*}\right.$, $\left.0,0^{*}, \bar{D}\right)$ are in the main text. His beliefs after first-period performance $\left(P, N^{*}\right.$, $\left.0,0^{*}, 0\right)$ are very similar. It is straightforward to verify that $\alpha\left(N, N^{*}, 0,0^{*}, \bar{D}\right)$, $\alpha\left(N, N^{*}, 0,0^{*}, 0\right), \alpha^{*}\left(P, P^{*}, 0,0^{*}, \bar{D}\right)$, and $\alpha^{*}\left(P, P^{*}, 0,0^{*}, 0\right)$ all are equal to one. Similarly updated beliefs $\alpha\left(P, P^{*}, 0,0^{*}, \bar{D}\right)$ and $\alpha\left(P, P^{*}, 0,0^{*}, 0\right)$ are equal to $\lambda_{I}$, and updated beliefs $\alpha^{*}\left(N, N^{*}, 0,0^{*}, \bar{D}\right)$ and $\alpha^{*}\left(N, N^{*}, 0,0^{*}, 0\right)$ are equal to $\lambda_{I}^{*}$. Track records $\left(N, P^{*}, 0,0^{*}, \bar{D}\right)$ and $\left(N, P^{*}, 0,0^{*}, 0\right)$ are out of equilibrium events and therefore not constrained by Bayes' rule. We assume that beliefs of both the domestic and the foreign voter are equal to one in this case, which is the most unfavourable assumption possible.

The re-election probability $h\left(h^{*}\right)$ of the domestic (foreign) incumbent before damages are realized is

$$
\begin{aligned}
h\left(E, E^{*}, T, T^{*}, \theta\right)= & \theta G\left(\alpha\left(E, E^{*}, T, T^{*}, \bar{D}\right)\right)+(1-\theta) \\
& G\left(\alpha\left(E, E^{*}, T, T^{*}, 0\right)\right) \\
h^{*}\left(E, E^{*}, T, T^{*}, \theta\right)= & \theta G\left(\alpha^{*}\left(E, E^{*}, T, T^{*}, \bar{D}\right)\right)+(1-\theta) \\
& G\left(\alpha^{*}\left(E, E^{*}, T, T^{*}, 0\right)\right),
\end{aligned}
$$

which are a function of the indicated variables and $\lambda_{I}$ and $\lambda_{I}^{*}$.

To establish the existence of the equilibrium two deviations from the equilibrium strategy have to be ruled out for each incumbent. First, given the other incumbent's strategy and the initial reputations $\lambda_{I}$ and $\lambda_{I}^{*}$, bad domestic (foreign) incumbents must prefer $P\left(N^{*}\right)$ to $N\left(P^{*}\right)$, regardless of the state $\theta$. 
The payoff to a bad domestic incumbent of implementing $P$ in state $\theta_{0}$, when both good and bad foreign incumbents always implement $N^{*}$ under the equilibrium strategy is

$$
v_{b}\left(P, N^{*}, 0, \theta_{0}\right)+h\left(P, N^{*}, 0,0^{*}, \theta_{0}\right) \beta \hat{v}_{b}(\hat{T}),
$$

which has to be greater than the payoff of selecting $E=N$, which is $v_{b}\left(N, N^{*}\right.$, $\left.0, \theta_{0}\right)+\delta \hat{v}_{b}(\hat{T})$. This can be rearranged to yield

$$
v_{b}\left(P, N^{*}, 0, \theta_{0}\right)-v_{b}\left(N, N^{*}, 0, \theta_{0}\right)>\left[1-h\left(P, N^{*}, 0,0^{*}, \theta_{0}\right)\right] \beta \hat{v}_{b}(\hat{T}) .
$$

The left-hand side of (A4) is the gain in first-period utility of a bad incumbent if he implements the environmental policy $(E=N)$ if $E^{*}=N^{*}$ and $\theta=\theta_{0}$. The righthand side of (A4) is the resulting reduction in his re-election probability multiplied by the discounted second-period payoff $\beta \hat{v}_{b}(\hat{T})$. As $h\left(P, E^{*}, 0,0^{*}, \theta_{0}\right) \geq 0$, there is always a critical value of $\psi_{1}$ (as defined in assumption 2 ) above that this inequality holds. The same critical value of $\psi_{1}$ ensures that very similar inequalities hold when the state is $\theta_{1}$ or $E^{*}=P^{*}$. If $E^{*}=N^{*}$ and the state $\theta=\theta_{1}$, then the left-hand side of (A4) would be replaced with an even larger term and the right-hand side would be smaller, as the re-election probability after selecting $E=P$ is larger when $\theta=\theta_{1}$. For $E^{*}=P^{*}$ and $\theta=\theta_{1}$ (which is the only other possible combination of states and foreign policy choices under the equilibrium strategies) the right-hand side of (A4) would also be replaced with a smaller term, as $h\left(P, P^{*}, 0,0^{*}\right.$, $\left.\theta_{1}\right)=\lambda_{I}>h\left(P, N^{*}, 0,0^{*}, \theta_{0}\right)$. Furthermore the left-hand side of (A4) would be be replaced by a larger term, as the domestic price is lower if $E^{*}=P^{*}$ rather than $E^{*}=N^{*}$ (see the discussion in section 2.2), which implies that domestic welfare is higher and profits are lower in this case. The strict concavity of $v_{b}$ in both welfare and income of the local producer ensures that a bad domestic politician will now have an even larger first period payoff from implementing the environmental policy relative to the case where $E^{*}=N^{*}$ and $\theta=\theta_{1}$.

The same method can be used to rule out a foreign bad incumbent's preferring $P^{*}$ to $N^{*}$ in state $\theta_{1}$ when both good and bad domestic incumbents always implement $E=P$ under the equilibrium strategy. The payoff from selecting $E^{*}=N^{*}$ is

$$
v_{b}^{*}\left(P, N^{*}, 0^{*}, \theta_{1}\right)+h^{*}\left(P, N^{*}, 0,0^{*}, \theta_{1}\right) \beta \hat{v}_{b}^{*}\left(\hat{T}^{*}\right) .
$$

This has to be larger than the payoff from $E^{*}=P^{*}$, which is $v_{b}{ }^{*}\left(P, P^{*}, 0^{*}, \theta_{1}\right)+\delta \hat{v}_{b} *\left(\hat{T}^{*}\right)$. This yields

$$
\begin{gathered}
v_{b} *\left(P, N^{*}, 0^{*}, \theta_{1}\right)-v_{b}^{*}\left(P, P^{*}, 0^{*}, \theta_{1}\right) \\
>\left[1-h^{*}\left(P, N^{*}, 0,0^{*}, \theta_{1}\right)\right] \beta \hat{v}_{b}^{*}\left(\hat{T}^{*}\right),
\end{gathered}
$$

which is very similar to (A4). A sufficiently large value of $\psi_{1}^{*}$ ensures that (A6) holds. Very similar arguments to those for the case of a bad domestic incumbent establish that the same $\psi_{1}^{*}$ ensures that (A6) also holds when $E=P$ and $\theta=\theta_{0}$ or $E=N$ and $\theta=\theta_{0}$. 
The second possible deviation from the equilibrium strategy would be for bad incumbents to make a direct transfer in the first period. For a bad domestic incumbent in state $\theta_{0}$, the payoff under the equilibrium strategy is (A3), which has to be larger than $\hat{v}_{b}\left(N, N^{*}, \hat{T}, \theta_{0}\right)$, the payoff of selecting a first-period direct transfer. This implies that

$$
\left[h\left(P, N^{*}, 0,0^{*}, \theta_{0}\right)\right] \beta \hat{v}_{b}(\hat{T})>\hat{v}_{b}\left(N, N^{*}, \hat{T}, \theta_{0}\right)-v_{b}\left(P, N^{*}, 0, \theta_{0}\right)
$$

has to hold. Assumption 2 implies that $v_{b}\left(P, N^{*}, 0, \theta_{0}\right)>v_{\mathrm{b}}\left(N, N^{*}, 0, \theta_{0}\right)$, and a sufficiently large $\psi_{2}$ (as defined in the main text) therefore ensures that this inequality is satisfied. Very similar arguments can be used to show that the same critical value of $\psi_{2}$ that just satisfies (A7) is also sufficient to rule out a deviation from the equilibrium strategy if $E^{*}=N^{*}$ and $\theta=\theta_{1}$ or $E^{*}=P^{*}$ and $\theta=\theta_{1}$.

Finally, the same method can be used to rule out a bad foreign incumbent's wanting to deviate to a direct transfer in the first period. In state $\theta_{1}$, his payoff under the equilibrium strategy is (A5), and his payoff under the optimal direct transfer is $\hat{v}_{b}{ }^{*}\left(P, E^{*}, \hat{T}^{*}, \theta_{1}\right)$, which implies the following inequality:

$$
\left[h^{*}\left(P, N^{*}, 0,0^{*}, \theta_{1}\right)\right] \beta \hat{v}_{b}^{*}\left(\hat{T}^{*}\right)>\hat{v}_{b}^{*}\left(P, P^{*}, \hat{T}^{*}, \theta_{1}\right)-v_{b}^{*}\left(P, N^{*}, 0^{*}, \theta_{1}\right) .
$$

Assumption 2 implies that $v_{b} *\left(P, N^{*}, 0^{*}, \theta_{1}\right)>v_{b} *\left(P, P^{*}, 0^{*}, \theta_{1}\right)$, and a sufficiently large $\psi_{2}^{*}$ therefore ensures that the inequality holds. As before, any value of $\psi_{2}^{*}$ that satisfies (A8) also rules out deviations from the equilibrium strategy if $E=N$ and $\theta=\theta_{0}$ or $E=P$ and $\theta=\theta_{0}$.

QED

\section{Proof of corollary 1}

Let $\alpha(E, 0, D)$ denote the domestic voter's updated beliefs about the quality of his incumbent if the voter can observe only the policy choices in the home country and there is no transfer. Similarly, let $\alpha^{*}\left(E^{*}, 0, D\right)$ be the equivalent beliefs for the foreign voter if he cannot observe policy making in the home country. It is straightforward to show that $\alpha(P, 0, D)$ is increasing in $\lambda_{I}, \alpha(P$, $0, D)=\alpha\left(P, N^{*}, 0,0^{*}, D\right)$ if $\lambda_{I}^{*}=0$ and $\alpha(P, 0, D)>\alpha\left(P, N^{*}, 0,0^{*}, D\right)$ if $\lambda_{I}{ }^{*}>0$. Similarly, it is also the case that $\alpha^{*}\left(N^{*}, 0^{*}, D\right)$ is increasing in $\lambda_{I^{*}}$, $\alpha^{*}\left(N^{*}, 0^{*}, D\right)=\alpha^{*}\left(P, N^{*}, 0,0^{*}, D\right)$ if $\lambda_{I}=0$ and $\alpha^{*}\left(N^{*}, 0^{*}, D\right)>\alpha^{*}\left(P, N^{*}\right.$, $\left.0,0^{*}, D\right)$ if $\lambda_{I}>0$. Now, suppose that there is a trade dispute, so $E=P$ and $E^{*}=N^{*}$, and that for the set of initial reputations $\lambda_{I}$ and $\lambda_{I}^{*}$ and parameters $\psi_{1}, \psi_{1}^{*}, \psi_{2}, \psi_{2}^{*}$ at least one of the inequalities (A4), (A6), (A7), or (A8) is binding in the case where policy choices are observable in both countries. If the policy choices in the other country are, instead, unobservable, then the resulting improvement in voters' assessment of the quality of their respective incumbents will increases the incumbents' re-election probability. This relaxes the inequalities (A4), (A6), (A7), and (A8), and for given values of $\psi_{1}, \psi_{1}^{*}, \psi_{2}, \psi_{2}^{*}$ a larger set of initial reputations $\lambda_{I}$ and $\lambda_{I}^{*}$ would therefore satisfy these four inequalities. QED 


\section{References}

Aidt, Toke S. (1998) 'Political internalization of economic externalities and environmental policy,' Journal of Public Economics 69, 1-16

Alesina, Alberto, Reza Baqir, and William Easterly (2000) 'Redistributive public employment,' Journal of Urban Economics 48, 219-41

Alesina, Alberto, Stephan Danninger, and Massimo Rostagno (2001) 'Redistribution through public employment: the case of Italy,' IMF Staff Papers 48, 447-73

Besley, Timothy, and Anne Case (1995a) 'Does electoral accountability affect economic policy choices? Evidence from gubernatorial term limits,' Quarterly Journal of Economics 60, 769-98

- (1995b) 'Incumbent behaviour: vote-seeking, tax-setting, and yardstick competition,' American Economic Review 85, 25-45

- (2003) 'Political institutions and policy choices: evidence from the United States,' Journal of Economic Literature 41, 7-73

Besley, Timothy, and Stephen Coate (1998) 'Sources of inefficiency in a representative democracy: a dynamic analysis,' American Economic Review 88, 139-56

Coate, Stephen, and Stephen Morris (1995) 'On the form of transfers to special interests,' Journal of Political Economy 103, 1210-35

Copeland, Brian R. (2001) 'Strategic environmental policy: product standards in a national treatment regime,' mimeo, University of British Columbia

Copeland, Brian R., and Scott M. Taylor (2003) Trade and the Environment: Theory and Evidence (Princeton, NJ: Princeton University Press)

Engel, Eduardo M. (2000) 'Poisoned grapes, mad cows and protectionism,' Journal of Policy Reform 4, 91-111

Esty, Daniel C. (1994) Greening the Gatt: Trade, Environment and the Future (Washington, DC: Institute of International Economics)

Fischer, Ronald, and Pablo Serra (2000) 'Standards and protection,' Journal of International Economics 52, 377-400

Fredriksson, Per G. (1997) 'The political economy of pollution taxes in a small open economy,' Journal of Environmental Economics and Management 33, 44-58

Hillman, Arye L., and Heinrich W. Ursprung (1992) 'The influence of environmental concerns on the political determination of trade policy,' in The Greening of World Trade Issues, ed. K. Anderson and R. Blackhurst (Ann Arbor: University of Michigan Press)

- (1994) 'Greens, supergreens and international trade policy: environmental concerns and trade policy,' in Trade, Innovation, Environment, ed. C. Carraro (Dordrecht: Kluwer Academic)

Laplante, Benoit, and Jonathan Garbutt (1992) 'Environmental protectionism,' Land Economics 68, 116-19

List, John A., and Daniel M. Sturm (2006) 'How elections matter: theory and evidence from environmental policy,' Quarterly Journal of Economics, forthcoming

Rauscher, Michael (1997) International Trade, Factor Movements, and the Environment (Oxford: Oxford University Press)

Sorsa, Piritta (1995) 'Environmental protectionism, north-south trade and the Uruguay Round,' IMF Working Paper 95/6

Sturm, Daniel M. (2003) 'Trade and the environment: a survey of the literature,' in Environmental Policy in an International Perspective, ed. L. Marsiliani, M. Rauscher, and C. Withagen (Dordrecht: Kluwer Academic)

Tian, Huilan (2003) 'Eco-labelling scheme, environmental protection and protectionism,' Canadian Journal of Economics 36, 608-33 
Tullock, Gordon (1983) Economics of Income Redistribution (Boston, MA: KluwerNijhoff )

- (1989) The Economics of Special Privilege and Rent Seeking (Boston, MA: KluwerNijhoff)

Vogel, David (1995) Trading Up: Consumer and Environmental Regulation in a Global Economy (Cambridge, MA: Harvard University Press) 